\title{
International Journal of Research SCIENCE \& MANAgement HIGH ADMISSION PLASMA OSMOLALITY VALUE AS IN-HOSPITAL MAJOR ADVERSE CARDIOVASCULAR EVENTS PREDICTOR IN PATIENT WITH ACUTE MYOCARDIAL INFARCTION Zul Bahri", Cut Aryfa Andra ${ }^{1}$, Zulfikri Mukhtar ${ }^{1}$, Abdul Halim Raynaldo ${ }^{1}$, Yuke Sarastri ${ }^{1}$ \& Harris Hasan ${ }^{1}$ \\ ${ }^{1}$ Department of Cardiology and Vascular Medicine, Faculty of Medicine, Universitas Sumatera Utara / Haji Adam Malik General Hospital, Medan, North Sumatera, Indonesia
}

DOI: https://doi.org/10.29121/ijrsm.v7.i11.2020.10

Keywords: Plasma osmolality, major adverse cardiovascular events, acute myocardial infarction.

\begin{abstract}
Background: Elevated blood urea nitrogen (BUN), blood glucose, and alteration sodium levels are common among patients with acute myocardial infarction (AMI). These parameters to be widely investigated to assess the prognosis in AMI patients. However, the combination of these parameters (BUN, blood glucose, and sodium) calculated by a certain formula in the form of plasma osmolality has not been widely studied to assess the prognosis of patients with acute myocardial infarction. This study aims to assess plasma osmolality in predicting hospital major adverse cardiovascular events (MACEs) among AMI patients.

Methods: Data were collected from 118 consecutive patients with AMI in Cardiac Centre Haji Adam Malik General Hospital Medan. We measured admission plasma osmolality [1,86 (Na+) + BUN/2,8 + Glucose/18+9]. Then we observed in hospital Major Adverse Cardiovascular Outcomes (MACEs) which consist of cardiovascular mortality, acute heart failure, malignant arrhythmia, and cardiogenic shock. Statistical analysis was performed using mean difference, logistic regression, and receiver operating curve (ROC).

Result: Among 118 patients, MACEs were observed in 49 (41.5\%) patients with the most common MACEs was acute heart failure (25.4\%). Bivariate analysis showed a significant relationship between the plasma osmolality and in hospital MACEs $(\mathrm{p}<0.001)$. The plasma osmolality AUC prediction value was $78.9 \%$. The optimal cutoff value was $279.9 \mathrm{mOsm} / \mathrm{kg}$ (sensitivity $81.6 \%$; specificity $75.4 \%$ ). In multivariate logistic regression analysis, the plasma osmolality was the strongest predictor with an OR value of 10.542 (95\% CI 2.694-41.255; p-value $<0.001)$.

Conclusions: Among AMI patients, high plasma osmolality value ( $\geq 280 \mathrm{mOsm} / \mathrm{kg})$ is a better predictor of inhospital MACEs than its components separately(BUN, glucose level, sodium).
\end{abstract}

\section{Introduction}

Cardiovascular disease still contributes to high morbidity and mortality rates at the global level. The World Heart Organization (WHO) states that as many as 17.9 million deaths in 2016 were caused by cardiovascular disease, this figure accounts for $44 \%$ of the causes of death from non-communicable diseases in the world, and an estimated 7.4 million deaths were caused by coronary heart disease. ${ }^{1}$ Acute coronary syndrome (ACS) is an acute manifestation of coronary heart disease with clinical spectrum of myocardial ischemia ranging from unstable angina pectoris (UAP) non-elevated ST-segment myocardial infarction (NSTEMI), and ST-segment elevation acute myocardial infarction (STEMI). ${ }^{2}$

Risk stratification in patients with ACS is crucial to provide optimal management. Many biomarkers and clinical characteristics have been identified to optimize risk factor guided therapy. ${ }^{3}$ A lot of laboratory parameters have been investigated and associated with mortality in ACS patients, some of these parameters are blood sugar levels, kidney function, and electrolytes. Acutely increasing blood sugar levels or hyperglycemic stress (HS) had proved to be associated with increased in-hospitals mortality in ACS patients with diabetes mellitus (DM), and without DM. ${ }^{4}$ High BUN level can predict mortality, acute myocardial infarction (AMI), and stroke independently compared to serum creatinine, glomerular filtration rate (GFR), and other biomarkers. ${ }^{5,6}$ Hyponatremia in the early phase of acute STEMI also has been demonstrated to be a predictor of long-term mortality and re-hospitalization of heart failure. ${ }^{7}$

The laboratory parameters mentioned above (blood glucose, BUN, and sodium) turned out to be components that contribute to plasma osmolality. ${ }^{8}$ Hyperosmolality was significantly associated with an increased 1-year mortality 


\section{International Journal of Research SCIEnCE \& MANagement}

rate in ACS patients undergoing percutaneous coronary intervention. ${ }^{3,9}$ Tatlisu et al in a larger study also showed that plasma osmolality has a strong association with increased both in the hospital and in the long term mortality. ${ }^{10}$ From the background that has been stated above, we can assume that plasma osmolality composed of blood glucose level, BUN, and sodium which have previously been studied and have a good value in predicting the prognosis of patients with AMI patients should be able to provide a better picture for patient prognosis.

\section{Methods}

\section{Population and Research Design}

This is a cohort study conducted at Cardiac Centre Haji Adam Malik General Hospital, Medan. Involving 118 consecutive patients based on inclusion and exclusion criteria from January 2020 to June 2020. Patients with a diagnosis of AMI were the population in this study.

After looking at medical record data, plasma osmolality was calculate based on admission laboratory results using the formula [1,86 $(\mathrm{Na}+)+$ BUN/2,8 + Glucose/18+9], then MACEs was observed during hospital stay which includes cardiovascular death, malignant arrhythmias, cardiogenic shock, and acute heart failure.

\section{Statistical analysis}

Categorical variables will be presented descriptively by displaying frequency distribution (n) and percentage (\%). Numerical variables are presented by mean values and standard deviations for normally distributed data, while data with abnormal distribution is presented in medians and minimum-maximum values. Comparison analysis between two groups used the T Independent test (T-test). The Mann Whitney test is used if the T Independent test requisitions are not met. A receiver Operator Characteristic (ROC) curve was used to determine the best cut-off value for plasma osmolality to predict MACEs, then prognostic significance was assessed with Area Under the Curve (AUC). Variables that are considered significant in the bivariate analysis will be included in the multivariate analysis with logistic regression and displayed on Odds Ratio (OR) with a 95\% confidence interval (CI). All data were processed and analyzed using SPSS version 24.0. The variable with p-value $<0.05$ is considered to be statistically significant.

\section{Results}

This study included 118 AMI patients who were admitted to Cardiac Centre Haji Adam Malik General Hospital, Medan. Most of the subjects were men (78.8\%) with an average age of 57.1 years old. Subjects with the majority of traditional cardiovascular risk factors were seen in this study, such as hypertension (54.2\%), diabetes mellitus (66.9\%), dyslipidemia (53.4\%), and smoking (78.8\%). Subjects with ST-segment elevation myocardial infarction (STEMI) were $77.1 \%$, and the rest were Non-ST-segment elevation myocardial infarction (NSTEMI). Clinical presentation with median systolic blood pressure was $125 \mathrm{mmHg}$ and the average heart rate was $85.5 \mathrm{bpm}$. Risk stratification was based on Killip class and GRACE score. Base on MACEs' findings, there were 49 subjects (41.5\%) having in-hospital MACEs, including acute heart failure (25.4\%), cardiogenic shock (7.6\%), malignant arrhythmia (6.8\%), and cardiovascular death (14.4\%). Other findings of the subjects of this study are presented in table 1 .

Tabel 1. Baseline Characteristics

\begin{tabular}{lc}
\hline Variables & $\mathbf{n = 1 1 8}$ \\
\hline Age (years old) & $57.1(10.4)$ \\
Male & $93(78.8 \%)$ \\
BMI $\left(\mathrm{kg} / \mathrm{m}^{2}\right)$ & $24.6(3.1)$ \\
Dyslipidemia & $63(53.4 \%)$ \\
Smoking & $93(78.8 \%)$ \\
Hypertension & $64(54.2 \%)$ \\
Diabetes Mellitus & $79(66.9 \%)$ \\
Clinical Characteristics & \\
Systolic Blood Pressure (mmHg) & $125(80-220)$ \\
Diastolic Blood Pressure (mmHg) & $80(50-130)$ \\
Heart Rate (bpm) & $85.5(23.1)$ \\
GRACE Score & $113(56-214)$ \\
LVEF $(\%)$ & $44.5(21-67)$ \\
\hline
\end{tabular}


International Journal of Research Science \& MANagement

\begin{tabular}{|c|c|}
\hline \multicolumn{2}{|l|}{ KILLIP Class } \\
\hline KILLIP II-III & $39(33.1)$ \\
\hline KILLIP I & 79 (66.9) \\
\hline \multicolumn{2}{|l|}{ Coronary lession } \\
\hline CAD1VD & $24(20.3 \%)$ \\
\hline CAD2VD & $20(16.9 \%)$ \\
\hline CAD3VD & $31(26.3 \%)$ \\
\hline \multicolumn{2}{|l|}{ Diagnosis } \\
\hline STEMI & $91(77.1 \%)$ \\
\hline NSTEMI & $27(22.9 \%)$ \\
\hline \multicolumn{2}{|l|}{ MACEs } \\
\hline Acute heart failure & $30(25.4 \%)$ \\
\hline Malignant arrhytmia & $8(6.8 \%)$ \\
\hline Cardiogenic shock & $9(7.6 \%)$ \\
\hline Cardiovascular mortality & $17(14.4 \%)$ \\
\hline \multicolumn{2}{|l|}{ Laboratory Characteristics } \\
\hline Hemoglobin $(\mathrm{g} / \mathrm{dl})$ & $13.4(2.1)$ \\
\hline Hematocrit (\%) & $40(19-53)$ \\
\hline Platelets (cell $/ \mu \mathrm{L}$ ) & $268,207(60,738)$ \\
\hline Leukocyte $($ cell $/ \mu \mathrm{L})$ & $12,935(5150-23290)$ \\
\hline Creatinine $(\mathrm{mg} / \mathrm{dL})$ & $1.09(0.5-7.1)$ \\
\hline $\mathrm{GFR}(\mathrm{ml} / \mathrm{min})$ & $69.3(34.1)$ \\
\hline Troponin I (ng/mL) & $4.02(0.02-32)$ \\
\hline CK-MB (ng/mL) & $89(6-684)$ \\
\hline Plasma osmolality (mOsm/kg) & $279(200.1-317.9)$ \\
\hline Sodium $(\mathrm{mEq} / \mathrm{L})$ & $136(121-149)$ \\
\hline BUN (mg/dL) & $17(6-88)$ \\
\hline Random blood glucose $(\mathrm{mg} / \mathrm{dL})$ & $151.5(83-547)$ \\
\hline \multicolumn{2}{|l|}{ Therapies } \\
\hline Dual anti-platelets therapy (DAPT) & $118(100 \%)$ \\
\hline ACE-Inh/ARB & $104(88.1 \%)$ \\
\hline Beta Blocker & $86(72.9 \%)$ \\
\hline Statin & $118(100 \%)$ \\
\hline \multicolumn{2}{|l|}{ Anticoagulants } \\
\hline Enoxaparin & $66(55.9 \%)$ \\
\hline Fondaparinux & $34(28.8 \%)$ \\
\hline Unfractioned Heparin & $18(15.3 \%)$ \\
\hline \multicolumn{2}{|l|}{ Revascularization Strategy } \\
\hline PCI & $56(47.5 \%)$ \\
\hline Conservative & $62(52.5 \%)$ \\
\hline
\end{tabular}

Bivariate analysis in table 2 shows some parameters that significantly different between the two groups. In baseline parameters, age and BMI were significantly different, with older patients and lower BMI were found in MACEs group. Clinical characteristics such as systolic and diastolic blood pressure (SBP and DBP), heart rate (HR) GRACE score, LVEF, and Killip Class also significantly different between the two groups. The laboratory characteristics of the subjects, including hemoglobin, hematocrit, leukocyte, creatinine, GFR, Troponin I, plasma osmolality, BUN, and blood glucose also found significantly different. MACEs group had a median osmolality value of $285 \mathrm{mOsm} / \mathrm{kg}$, BUN value of $26 \mathrm{mg} / \mathrm{dl}$, blood glucose level of $188 \mathrm{mg} / \mathrm{dl}$ and those value was higher in MACEs group compared with the non-MACEs group. While other laboratory parameters such as platelets, CKMB, and sodium level did not statistically significant differences between the two groups. The following table also shows that the revascularization strategy was not significant differences between the two groups. 


\begin{tabular}{|c|c|c|c|}
\hline Variables & $\begin{array}{c}\text { With MACEs } \\
(n=49)\end{array}$ & $\begin{array}{c}\begin{array}{c}\text { Without MACEs } \\
(n=69)\end{array} \\
\end{array}$ & $\mathbf{P}$ \\
\hline Age, (years old) & $60.71(11.32)$ & $54.59(9.07)$ & 0.002 \\
\hline Male & $38(40.9)$ & $55(59.1)$ & 0.957 \\
\hline BMI $\left(\mathrm{kg} / \mathrm{m}^{2}\right)$ & $23.90(3.13)$ & $25.11(3.12)$ & 0.041 \\
\hline Dyslipidemia & $24(38.1)$ & $39(61.9)$ & 0.534 \\
\hline Smoking & $38(40.9)$ & $55(59.1)$ & 0.957 \\
\hline Hypertension & $26(40.6)$ & $38(59.4)$ & 0.977 \\
\hline Diabetes Mellitus & $34(43)$ & $45(57)$ & 0.783 \\
\hline \multicolumn{4}{|l|}{ Clinical Characteristics } \\
\hline Systolic Blood Pressure (mmHg) & $110(80-170)$ & $130(90-220)$ & $<0.001$ \\
\hline Diastolic Blood Pressure (mmHg) & $70(50-130)$ & $80(60-120)$ & 0.02 \\
\hline Heart Rate (bpm) & $96.12(26.48)$ & $78.01(17.16)$ & $<\mathbf{0 . 0 0 1}$ \\
\hline \multicolumn{4}{|l|}{ GRACE Score } \\
\hline$>108$ & $44(64.7)$ & $24(35.3)$ & \multirow[t]{2}{*}{$<0.001$} \\
\hline$\leq 108$ & $5(10)$ & $45(90)$ & \\
\hline \multicolumn{4}{|l|}{ LVEF $(\%)$} \\
\hline$<40$ & $27(77.1)$ & $8(22.9)$ & \multirow[t]{2}{*}{$<0.001$} \\
\hline$\geq 40$ & $22(26.5)$ & $61(73.5)$ & \\
\hline \multicolumn{4}{|l|}{ KILLIP Class } \\
\hline KILLIP II-III & $29(74.4)$ & $10(25.6)$ & \multirow{2}{*}{0.001} \\
\hline KILLIP I & $20(25.3)$ & $59(74.7)$ & \\
\hline \multicolumn{4}{|l|}{ Laboratory Characteristics } \\
\hline Hemoglobin (g/dL) & $12.83(2.19)$ & $13.82(2.00)$ & 0.015 \\
\hline Hematokrit $(\%)$ & $37.74(6.59)$ & $40.49(5.76)$ & 0.021 \\
\hline Leukocyte $($ cell $/ \mu \mathrm{L})$ & $14,409.18(4,756.20)$ & $12,624.43(3,710.97)$ & 0.031 \\
\hline Platelets $($ cell $/ \mu \mathrm{L})$ & $260,000(112,000-559,000)$ & $262,000(146,000-388,000)$ & 0.915 \\
\hline Creatinin (mg/dL) & $1.37(0.51-7.18)$ & $1.00(0.59-4.05)$ & 0.005 \\
\hline GFR (ml/min) & $44(6-149)$ & $81(12-145)$ & $<0.001$ \\
\hline Troponin I (ng/mL) & $6.47(0.31-32.00)$ & $2.50(0.02-32)$ & 0.003 \\
\hline CK-MB (ng/mL) & $89(6-536)$ & $89(18-685)$ & 0.915 \\
\hline Plasma Osmolality (mOsm/kg) & $285(265.39-317.98)$ & $274.78(200.19-298.42)$ & $<0.001$ \\
\hline Sodium $(\mathrm{mEq} / \mathrm{L})$ & $137(122-145)$ & $136(121-149)$ & 0.331 \\
\hline BUN (mg/dL) & $26(7-88)$ & $13(6-85)$ & $<0.001$ \\
\hline Random Blood Glucose (mg/dL) & $188(83-547)$ & $134(84-460)$ & 0.015 \\
\hline \multicolumn{4}{|l|}{ Revascularization Strategy } \\
\hline PCI & $19(33.9)$ & $37(66.1)$ & \multirow{2}{*}{0.160} \\
\hline Conservative & $30(48.4)$ & $32(51.6)$ & \\
\hline
\end{tabular}

The plasma osmolality cut-off value was obtained using the ROC curve as shown in Figure 1. The AUC value to predict MACEs was $78.9 \%$ with a p-value $<0.001$. The best cut-off value was $279.9 \mathrm{mOsm} / \mathrm{kg}$, with a sensitivity of $81.6 \%$, and specificity of $75.4 \%$. 


\section{International Journal of Research SCIEnCE \& MANagement}

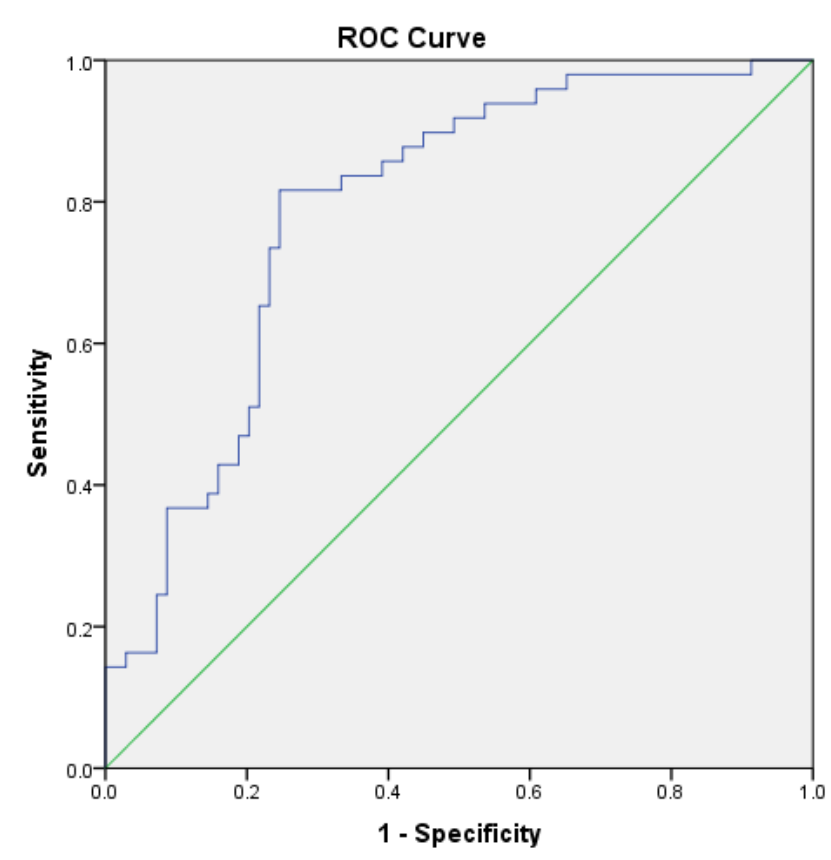

Figure 1 ROC Curve of Plasma Osmolality

Table 4. Multivariate Analysis to Predict MACEs in MI Patients

\begin{tabular}{lcccc}
\hline & \multirow{2}{*}{ Variables } & P value & Coefficient & \multicolumn{2}{c}{ CI 95\% } \\
& & (OR) & Min & Max \\
\hline GRACE score & 0.008 & 6.409 & 1.642 & 25.015 \\
KILLIP Class & 0.010 & 5.058 & 1.464 & 17.476 \\
Heart Rate & 0.026 & 5.363 & 1.221 & 23.565 \\
Plasma Osmolality & 0.001 & 10.542 & 2.694 & 41.255 \\
BUN & 0.016 & 4.259 & 1.307 & 13.873 \\
\hline
\end{tabular}

The final results of multivariate analysis showed that there were five independent factors predicting MACE: GRACE Score, KILLIP Class, heart rate, plasma osmolality, and BUN. The plasma osmolality was the strongest predictor with an OR value of 41.225 (p-value 0.001).

\section{Discussion}

High plasma osmolality value was related to poor clinical outcomes in patients with ACS. A Previous study conducted by Rohla et al stated that there was a relationship between increased admission plasma osmolality and mortality in ACS patients undergoing percutaneous coronary intervention (PCI). ${ }^{3}$ Other study conducted by Tatlisu et al found that there was a strong relationship between plasma osmolality within 8 hours of admission in STEMI patients undergoing primary PCI and increased in-hospital and long mortality Patients with an osmolality value $299 \pm 5.2 \mathrm{mOsm} / \mathrm{kg}$ had 3.7 times higher in-hospital mortality and 3.2 times higher long-term mortality compared to lower plasma osmolality values. The plasma osmolality cut-off value for mortality during the hospital stay was $292.9 \mathrm{mOsmol} / \mathrm{kg}$ with a sensitivity of $63 \%$ and a specificity of $70 \% .10$

In the present study, from a total of 118 samples, there were 49 patients $(41.5 \%)$ who experienced MACEs. Where the most common MACEs were acute heart failure (25.4\%). This is linear with a previous study by Núñez-Gil et al, stated that heart failure being the most frequent complication of AMI. ${ }^{11}$ The plasma osmolality value in this study showed a significant difference between the MACEs group and the non-MACEs group. Median plasma osmolality was found to be higher in the MACEs group $(285 \mathrm{mOsm} / \mathrm{kg})$ than in the non-MACEs group (274.78 $\mathrm{mOsm} / \mathrm{kg}$ ). By using the ROC curve the researcher obtained the predictive value (AUC) of plasma osmolality to predict MACEs was $78.9 \%$. The best cut-off value was $279.9 \mathrm{mOsm} / \mathrm{kg}$ with $81.6 \%$ sensitivity and $75.4 \%$ specificity. In the bivariate analysis using cut-off value, patients at higher plasma osmolality group $(\geq 280 \mathrm{mosm} / \mathrm{kg})$ had a greater risk for in-hospital MACEs. The multivariate analysis showed that admission 


\section{International Journal of Research SCIEnCE \& MANagement}

plasma osmolality could be used as a predictor of in-hospital MACEs, as well as being the strongest predictor among other predictors that passed the multivariate test with $\mathrm{p}$-value $=0.001$ and OR 10.542 .

The results of this study are consistent with previous studies concluded that increased plasma osmolality is related to poor clinical outcome in patients with ACS. ${ }^{3,10}$ The differences between the present study and the previous were that the population in the previous study were ACS patients who underwent PCI, whereas in this study, not all subjects underwent PCI, but after analysis, there was no significant difference between the groups towards MACEs in the present study. Another difference was that the cut-off value of this study is lower than previous studies, this might be due to different population, this can be seen from the median plasma osmolality in this study population was $279 \mathrm{mOsm} / \mathrm{kg}$, lower than the previous study.

Two aspects have to be considered when interpreting the mechanisms underlying the increase in plasma osmolality. First, hyperosmolality is always accompanied by an increase in its major components such as hyperglycemia, which have separately been reported as factors that increase the risk of cardiac mortality. Second, hyperosmolality itself can cause a redistribution of body fluids, such as mobilization of body fluids from venous capacitance to the effective circulating volume and then increases the preload volume that leads to a worse outcome. $^{12}$

From the discussion above, the results of this study suggest the use of plasma osmolality to help ratify risks in AMI patients, in addition to being a good predictor of in-hospital MACEs, the calculation method is simple, and the cost of the examination is affordable.

\section{Limitations}

The present study was a single-center with a variety of clinical presentations of AMI, and revascularization strategies lead to bias. This was an analytic observational study, so the causal relationship cannot be established.

\section{Conclusions}

High plasma osmolality value can be a good predictor of in-hospital MACEs in AMI patients, and the best cutoff value obtained is $280 \mathrm{mOsm} / \mathrm{kg}$.

\section{Conflict of Interest}

The authors declare that there is no conflict of interest.

\section{References}

[1] WHO. (2018). World Health Statistics 2018: Monitoring Health for The SDGs, Sustainable Development Goals (Vol. 2).

[2] Kim, M. C., Kini, A. S., \& Fuster, V.( 2013). Definitions and Pathogenesis of Acute Coronary Syndromes. In R. A. Walsh, J. C. Fang, \& V. Fuster (Eds.), Hurst's the Heart Manual of Cariology (13th ed., p. 249). New York: Mc Graw Hill.

[3] Rohla, M., Freynhofer, M. K., Tentzeris, I., Farhan, S., Wojta, J., Huber, K., \& Weiss, T. W. (2014). Plasma osmolality predicts clinical outcome in patients with acute coronary syndrome undergoing percutaneous coronary intervention. European Heart Journal: Acute Cardiovascular Care 3(1): 84-92.

[4] Capes, S. E., Hunt, D., Malmberg, K., \& Gerstein, H. C. (2000). Stress hyperglycaemia and increased risk of death after myocardial infarction in patients with and without diabetes: A systematic overview. Lancet 355(9206): 773-778.

[5] Aronson, D., Hammerman, H., Beyar, R., Yalonetsky, S., Kapeliovich, M., Markiewicz, W., \& Goldberg, A. (2008). Serum blood urea nitrogen and long-term mortality in acute ST-elevation myocardial infarction. International Journal of Cardiology 127(3): 380-385.

[6] Kirtane, A. J., Leder, D. M., Waikar, S. S., Chertow, G. M., Ray, K. K., Pinto, D. S., ... Gibson, C. M. (2005). Serum blood urea nitrogen as an independent marker of subsequent mortality among patients with acute coronary syndromes and normal to mildly reduced glomerular filtration rates. Journal of the American College of Cardiology 45(11): 1781-1786.

[7] Goldberg, A., Hammerman, H., Petcherski, S., Nassar, M., Zdorovyak, A., Yalonetsky, S., ... Aronson, D. (2006). Hyponatremia and long-term mortality in survivors of acute ST-elevation myocardial infarction. Archives of Internal Medicine 166(7): 781-786. 


\section{International Journal of Research Science \& Management}

[8] Dorwart, W. V., \& Chalmers, L. (1975). Comparison of methods for calculating serum osmolality from chemical concentrations, and the prognostic value of such calculations. Clinical Chemistry 21(2): 190194.

[9] Farhan, S., Vogel, B., Baber, U., Sartori, S., Aquino, M., Chandrasekhar, J., ... Sharma, S. (2019). Calculated serum osmolality, acute kidney injury, and relationship to mortality after percutaneous coronary intervention. CardioRenal Medicine 9(3): 160-167.

[10] Tatlisu, M. A., Kaya, A., Keskin, M., Uzman, O., Borklu, E. B., Cinier, G., ... Eren, M. (2017). Can we use plasma hyperosmolality as a predictor of mortality for ST-segment elevation myocardial infarction. Coronary Artery Disease 28: 70-76.

[11] Núñez-Gil, I. J., García-Rubira, J. C., Luaces, M., Vivas, D., De Agustín, J. A., González-Ferrer, J. J., ... Fernández-Ortiz, A. (2010). Mild heart failure is a mortality marker after a non-ST-segment acute myocardial infarction. European Journal of Internal Medicine, 21(5), 439-443.

[12] Shen, Y., Cheng, X., Ying, M., Chang, H. T., \& Zhang, W. (2017). Association between serum osmolarity and mortality in patients who are critically ill: A retrospective cohort study. BMJ Open 7(5): 1-9. 